\title{
A new species of chimaera, Hydrolagus melanophasma sp. nov. (Chondrichthyes: Chimaeriformes: Chimaeridae), from the eastern North Pacific
}

\author{
KELSEY C. JAMES ${ }^{1}$, DAVID A. EBERT ${ }^{1,2,4}$, DOUGLAS J. LONG ${ }^{3,4} \&$ DOMINIQUE A. DIDIER $^{5}$ \\ ${ }^{\prime}$ Pacific Shark Research Center, Moss Landing Marine Laboratories, 8272 Moss Landing Road, Moss Landing, CA 95039, USA. \\ E-mail:kjames@mlml.calstate.edu \\ ${ }^{2}$ Research Associate, South African Institute for Aquatic Biodiversity, Private Bag 1015, Grahamstown, 6140, South Africa \\ ${ }^{3}$ Department of Natural Sciences, Oakland Museum of California, 1000 Oak Street, Oakland, CA 94607 \\ ${ }^{4}$ Research Associate, Department of Ichthyology, California Academy of Sciences, 55 Music Concourse Drive, San Francisco, CA, \\ 94118 \\ ${ }^{5}$ Department of Biology, Millersville University, P.O. Box 1002, Millersville, PA 17551 USA
}

\begin{abstract}
A new species of chimaera, Hydrolagus melanophasma sp. nov. (Chimaeridae), is described from the eastern North Pacific. It is distinct from other eastern Pacific chimaeroids by the following characteristics: a large slightly curved dorsal fin spine extending beyond dorsal fin apex, a long second dorsal fin of uniform height throughout, large pectoral fins extending beyond the pelvic fin insertion when laid flat, trifid claspers forked for approximately one-quarter the total clasper length and a uniform black coloration throughout. The new species is compared to other eastern Pacific members of the genus Hydrolagus including H. alphus, H. colliei, H. macrophthalmus, and H. mccoskeri. Remote Operated Vehicle (ROV) video footage has identified and documented Hydrolagus melanophasma from the Gulf of California. ROV observations suggest that individuals typically occur over soft-bottom habitats or cobble patches with minimal vertical relief. This is in contrast to other eastern Pacific Hydrolagus species that tend to occur in areas of high rocky relief. The known distribution of this new species at present extends from southern California, U.S.A., along the Pacific coast of Baja California, Mexico, and into the Gulf of California.
\end{abstract}

Key words: Chimaeridae, Hydrolagus, Gulf of California, new species

\section{Introduction}

The Chimaeridae (Holocephali: Chimaeriformes) is the most diverse of the three chimaeriform families, the other two being the Callorhinchidae and Rhinochimaeridae. The Chimaeridae are divided into two genera, which are distinguished by the presence, in Chimaera, or absence, in Hydrolagus, of an anal fin. The genus Chimaera has at least 11 species, while Hydrolagus has at least 21 valid species to date (Eschmeyer and Fricke 2009). Fourteen of the 21 Hydrolagus species are known to occur in the Pacific Ocean (Barnett et al. 2006, Didier 2004, Didier 2008, and Quaranta et al. 2006), with ten of those species having fairly restricted ranges in the Western Pacific. The Eastern Pacific by comparison has only four species of Hydrolagus: two of which are thought to be endemic to the Galapagos Islands, a third known only from the southeastern Pacific along the coasts of Chile and Peru, and the fourth, Hydrolagus colliei (Lay and Bennett, 1839), being the only described Hydrolagus species from the eastern North Pacific.

A second, undescribed species of Hydrolagus has long been recognized in the eastern North Pacific (Hubbs et al. 1979; Eschmeyer et al. 1983; Ebert 2003). This new species was first recognized as distinct in 1965 by the late Carl L. Hubbs (Scripps Institute of Oceanography) who collected two specimens along the Pacific coast of Baja California, Mexico. Subsequently, other specimens have been collected or captured on 
film by Remote Operated Vehicle (ROV) off of Southern and Baja California. Here we described this new species, Hydrolagus melanophasma sp. nov.

\section{Materials and methods}

Morphometric measurements follow Didier and Séret (2002) and Compagno et al. (1990) and were made to the nearest millimeter $(\mathrm{mm})$. A total of 37 body and eight lateral line canal measurements were taken point to point (Appendix 1).

Institutional abbreviations for the California Academy of Sciences (CAS), Los Angeles County Museum of Natural History (LACM), Museo Nacional de Historia Natural (MNHNC) and Scripps Institute of Oceanography (SIO) follow Leviton et al. (1985).

The Monterey Bay Aquarium Research Institute (MBARI) in 2003 conducted a deep-sea survey using a Remote Operated Vehicle (ROV) in the Gulf of California. The resultant ROV footage from these survey dives included several observations of an unidentified Hydrolagus species. Subsequently, the authors reviewed this video footage and determined that the species in question is in fact the new species herein described.

\section{Hydrolagus melanophasma sp. nov.}

Eastern Pacific Black Ghostshark

(Fig. 1-4; Tables 1, 2)

Hydrolagus sp.: Hubbs et al., 1979:5; Eschmeyer et al., 1983:59; Ebert, 2003:240-241, Ill.; Love et al., 2005:2.

Holotype: SIO 77-211, adult male, 926 mm TL, 577 mm BDL; Punta Pescadera, Baja California, Mexico, (234'ㅅ $\left.109^{\circ} 42^{\prime} \mathrm{W}\right), 30.5 \mathrm{~m}, 19$ May 1977, collected by L. Levinson and K. Martin by hook and line.

Paratype: LACM 39805-1, adult male, $982 \mathrm{~mm}$ TL, $631 \mathrm{~mm}$ BDL; West of Ensenada, Mexico, in U.S. waters, 915 m, 20 January 1980, collected by Hal Rainwater aboard the boat Juanaloa.

Nontype Specimens: SIO 68-89 (4 specimens), 930-1200 mm TL, Northwest of Isla Angel de la Guarda, Mexico (2942.0'N 113 $\left.{ }^{\circ} 56.7^{\prime} \mathrm{W}\right), 565-644 \mathrm{~m}, 18$ January 1968, by otter trawl. SIO 65-435 (2 specimens), (3053.2'N 118 4.7'W), 1155 m, 22 September 1965, by trap and setline. LACM 37753-1, (1 specimen), 900 mm TL, California, U.S.A. (32²6.5’ N $\left.119^{\circ} 45^{\prime} \mathrm{W}\right), 1400 \mathrm{~m}$, September 1978, aboard the Califia.

Diagnosis. A species of the genus Hydrolagus based on the absence of an anal fin. Hydrolagus melanophasma sp. nov. is distinguished from other chimaeroids by a blunt snout with minimal sloping from the orbit to the snout tip, a large slightly curved dorsal fin spine (25.9\% BDL) extending beyond first dorsal fin apex, and a long second dorsal fin (77.3-81.1\% BDL) of uniform height throughout. The pectoral fins are large, reaching beyond the pelvic fin insertion when laid flat, trifid claspers forked for 27-27.8\% of the total clasper length and the preopercular and oral lateral line canals branch separately or together from the infraorbital canal. Coloration after preservation is a uniform black with no distinct mottling or markings.

Description. Morphometric measurements of the holotype and paratype are presented in Table 1; proportional measurements presented below are of the holotype followed by the paratype in parentheses. A medium to large bodied Hydrolagus with a blunt snout that slopes minimally from the orbit to snout tip; eyes moderate size, length $22.2 \%$ (26.0\%) of head length. Snout-vent length is short, $60.1 \%$ BDL (56.9\%), nearly equal to pelvic-caudal space, 57.9\% BDL (60.1\%). Pectoral-pelvic space, 29.8\% BDL (32.2\%), is one-half snout-vent length. Skin firm and robust, not deciduous as in some Hydrolagus (Didier 2002, Didier 2008). Pectoral fins large, triangular, anterior margin 40.9\% BDL (38.5\%), extends to or beyond pelvic fin insertion when laid against the body. Anterior margin of pelvic fins straight, length about one-half of pectoral fin anterior margin, $21.0 \%$ BDL (19.5\%); pelvic fin posterior margin convex. 
TABLE 1. Morphometric measurements as a proportion of body length (\%BDL) of holotype and paratype material.

\begin{tabular}{|c|c|c|}
\hline \multirow[b]{4}{*}{ Measurement } & \multicolumn{2}{|l|}{ H. melanophasma } \\
\hline & Holotype (male) & Paratype (male) \\
\hline & SIO 77-211 & LACM 39805-1 \\
\hline & $\% \mathrm{BDL}$ & $\% \mathrm{BDL}$ \\
\hline BDL (mm) & 577 & 631 \\
\hline TL & 160.5 & 155.6 \\
\hline PCL & 126.9 & 121.9 \\
\hline SVL & 60.1 & 56.9 \\
\hline TRL & 37.3 & 35.5 \\
\hline HDL & 29.5 & 25.0 \\
\hline POR & 10.6 & 11.5 \\
\hline PRN & 7.1 & 8.2 \\
\hline POB & 13.7 & 13.2 \\
\hline EYL & 6.5 & 6.5 \\
\hline EYH & 4.1 & 4.4 \\
\hline PD2 & 47.8 & 47.4 \\
\hline PD1 & 27.4 & 27.7 \\
\hline D1B & 15.3 & 13.9 \\
\hline DSA & 25.9 & 25.9 \\
\hline $\mathrm{D} 1 \mathrm{H}$ & 19.5 & 19.0 \\
\hline D2B & 81.1 & 77.3 \\
\hline $\mathrm{D} 2 \mathrm{H}$ & 4.0 & 4.1 \\
\hline IDS & 6.4 & 9.0 \\
\hline CDM & 23.1 & 20.5 \\
\hline $\mathrm{CDH}$ & 2.0 & 3.3 \\
\hline CTL & 33.3 & 34.5 \\
\hline CVM & 28.8 & 26.0 \\
\hline $\mathrm{CVH}$ & 2.4 & 2.9 \\
\hline $\mathrm{CPH}$ & 2.4 & 2.4 \\
\hline P1A & 40.9 & 38.5 \\
\hline $\mathrm{P} 2 \mathrm{~A}$ & 21.0 & 19.5 \\
\hline $\mathrm{P} 2 \mathrm{P}$ & 29.8 & 32.2 \\
\hline PCA & 57.9 & 60.1 \\
\hline D1P1 & 19.6 & 16.4 \\
\hline D1P2 & 39.5 & 42.5 \\
\hline D2P1 & 25.6 & 26.6 \\
\hline $\mathrm{D} 2 \mathrm{P} 2$ & 20.3 & 24.6 \\
\hline CLT & 15.0 & 13.7 \\
\hline CLM & 4.0 & 3.8 \\
\hline CLL & 3.9 & 4.2 \\
\hline FTL & 4.4 & 3.6 \\
\hline
\end{tabular}


TABLE 2. Morphometric measurements as a proportion of head length (\% HDL) of head lateral line canals of holotype and paratype material.

\begin{tabular}{|c|c|c|}
\hline \multirow[b]{4}{*}{ Measurement } & \multicolumn{2}{|l|}{ H. melanophasma } \\
\hline & Holotype (male) & Paratype (male) \\
\hline & SIO 77-211 & LACM 39805-1 \\
\hline & $\% \mathrm{HDL}$ & $\% \mathrm{HDL}$ \\
\hline HDL (mm) & 170.0 & 158.0 \\
\hline ONC & 8.2 & 8.8 \\
\hline LRC & 3.8 & 4.1 \\
\hline LNC & 26.0 & 28.0 \\
\hline IOA & 14.9 & 16.1 \\
\hline OTM & 30.6 & 32.9 \\
\hline OCL & 11.1 & 11.9 \\
\hline STL & 14.5 & 15.6 \\
\hline SPS & 16.9 & 18.2 \\
\hline
\end{tabular}

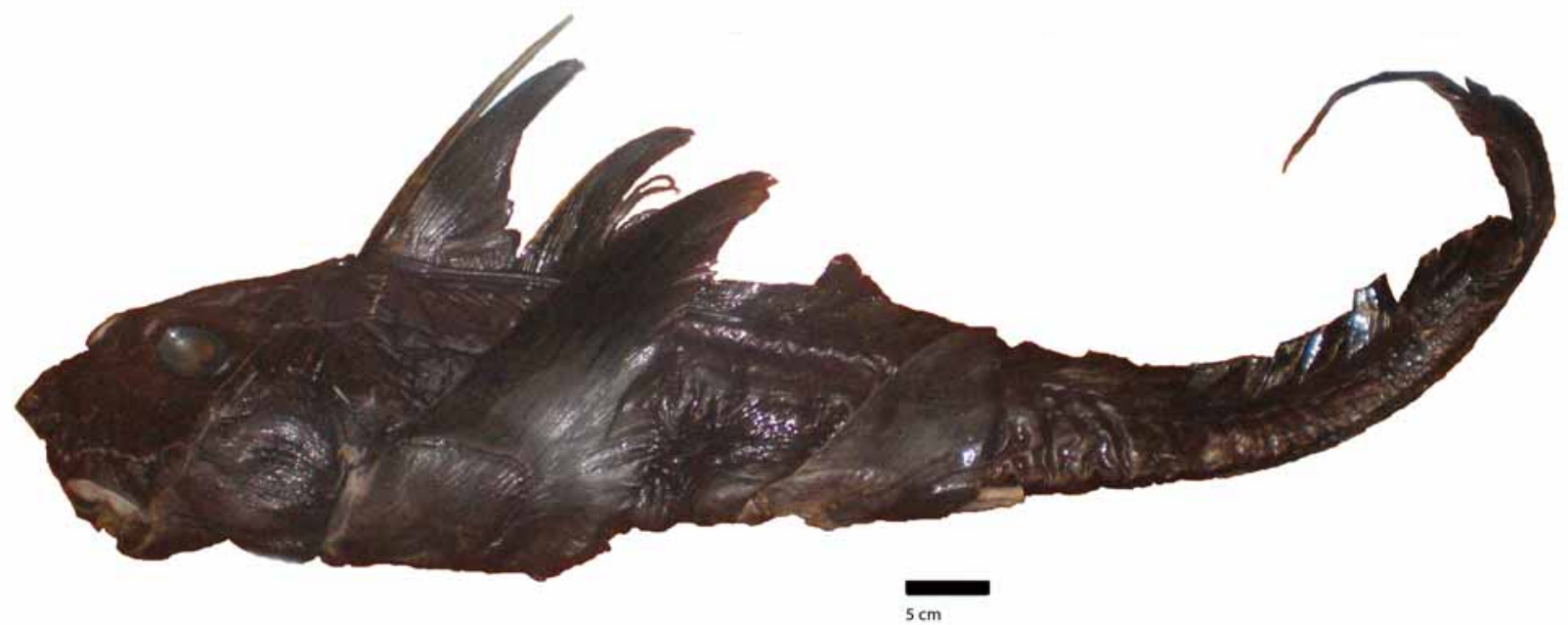

FIGURE 1. Holotype of Hydrolagus melanophasma sp. nov., SIO 77-211, adult male, $926 \mathrm{~mm}$ TL, $577 \mathrm{~mm}$ BDL, collected in the Gulf of California.

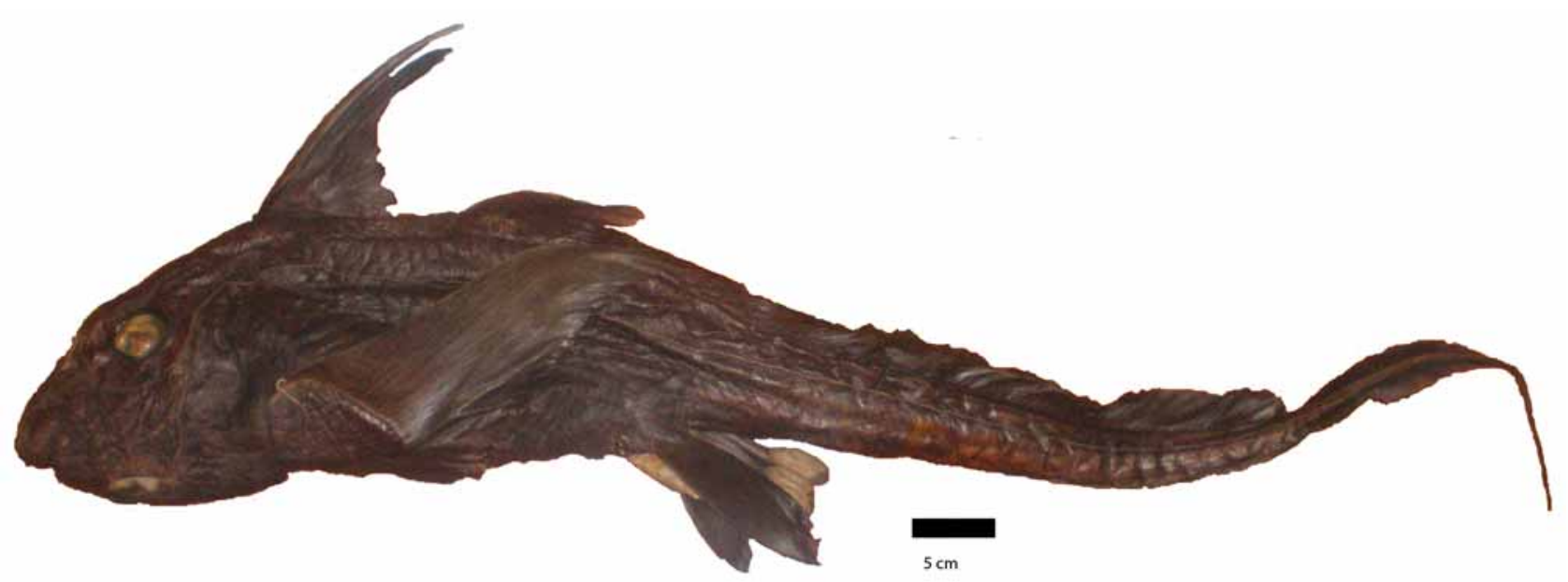

FIGURE 2. Paratype of Hydrolagus melanophasma sp. nov., LACM 39805-1, adult male, $982 \mathrm{~mm}$ TL, $631 \mathrm{~mm}$ BDL, collected in U.S. waters West of Ensenada. 

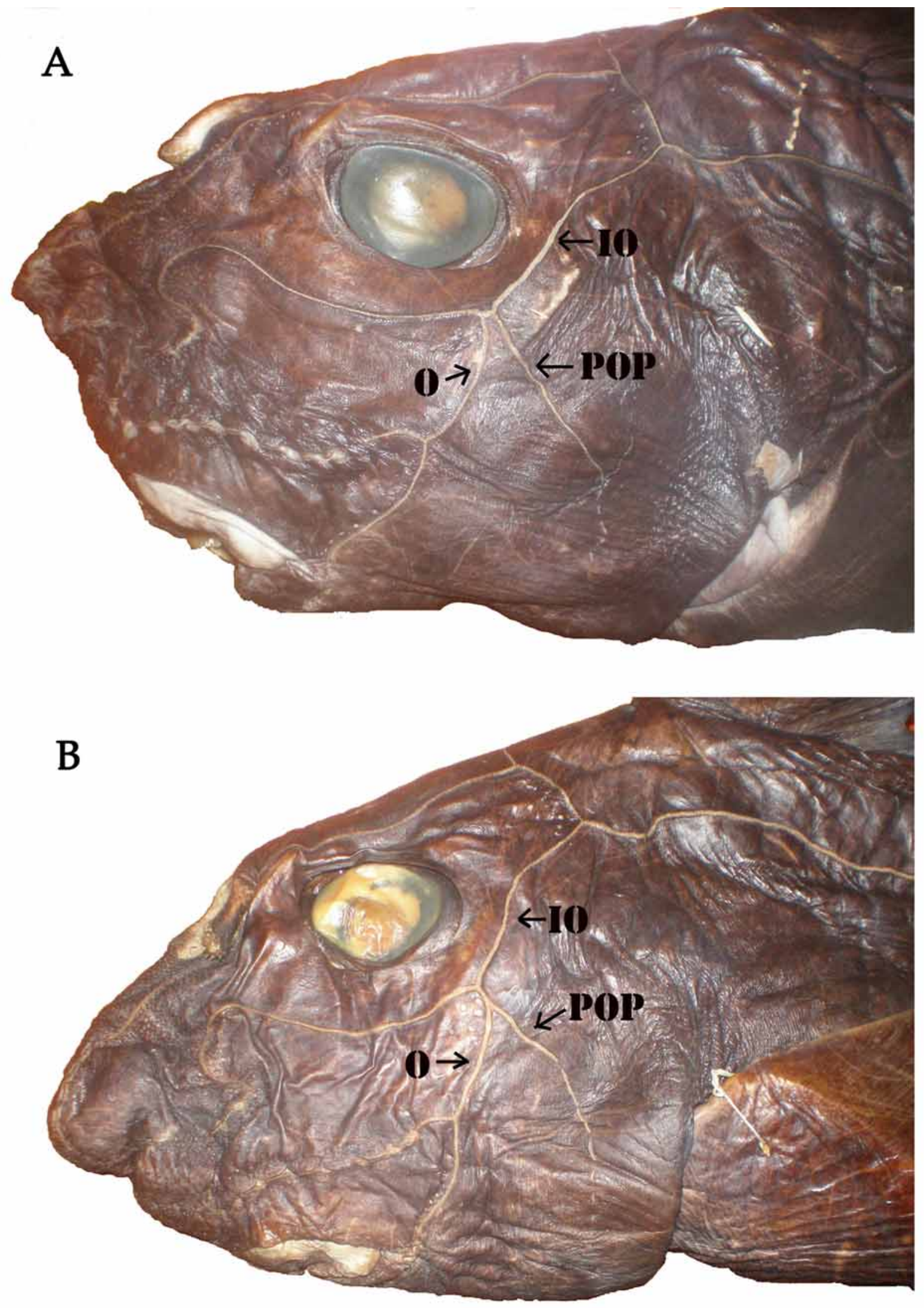

FIGURE 3. Intraspecific comparison of head lateral line canals of Hydrolagus melanophasma sp. nov. A) Holotype (SIO 77-211) preopercular (POP) and oral (O) lateral line canals branch separately from the infraorbital (IO) canal. B) Paratype (LACM 39805-1) preopercular (POP) and oral (O) lateral line canals branch together from the infraorbital (IO) canal and share a short common branch. 


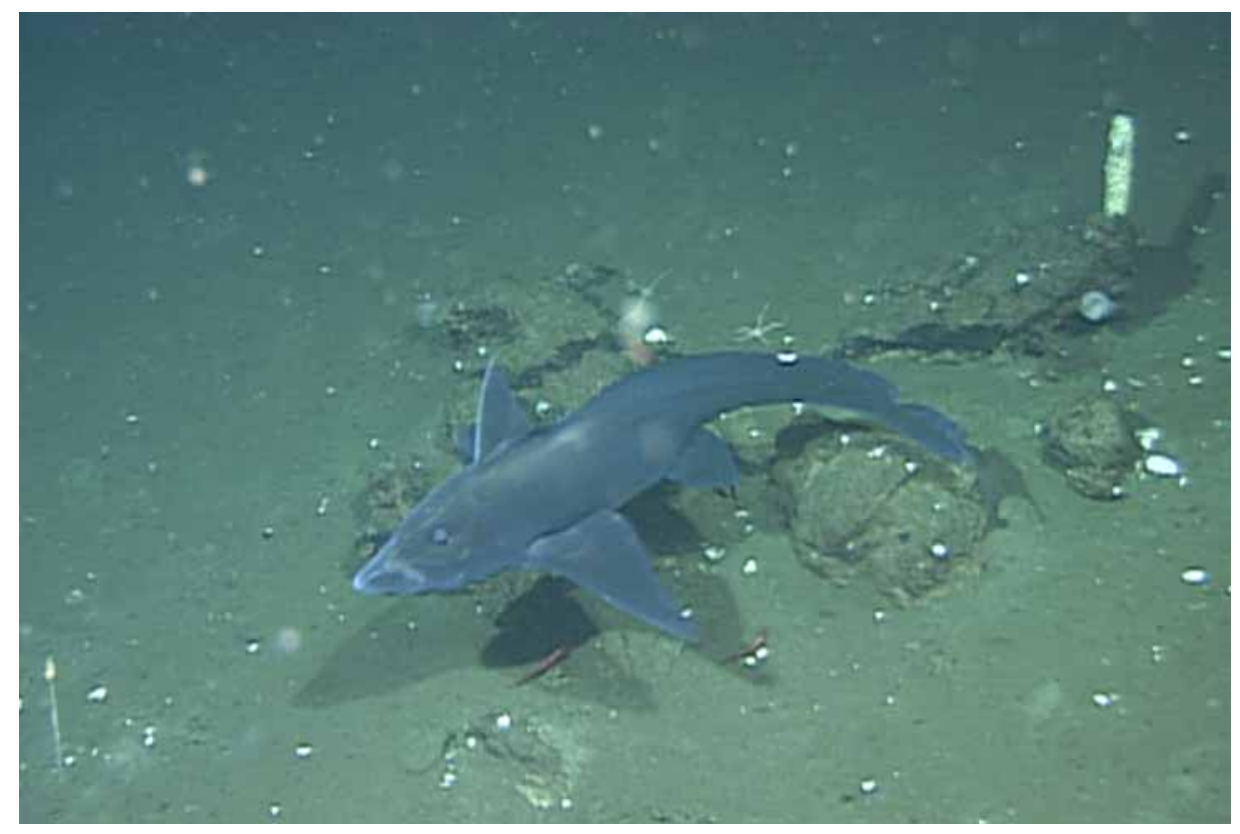

FIGURE 4. Photograph of a live specimen of Hydrolagus melanophasma sp. nov. at $1663.5 \mathrm{~m}$ in the Gulf of California from the 2003 MBARI ROV Tiburon surveys (36.757'N 111.454'W). (C) 2003 MBARI

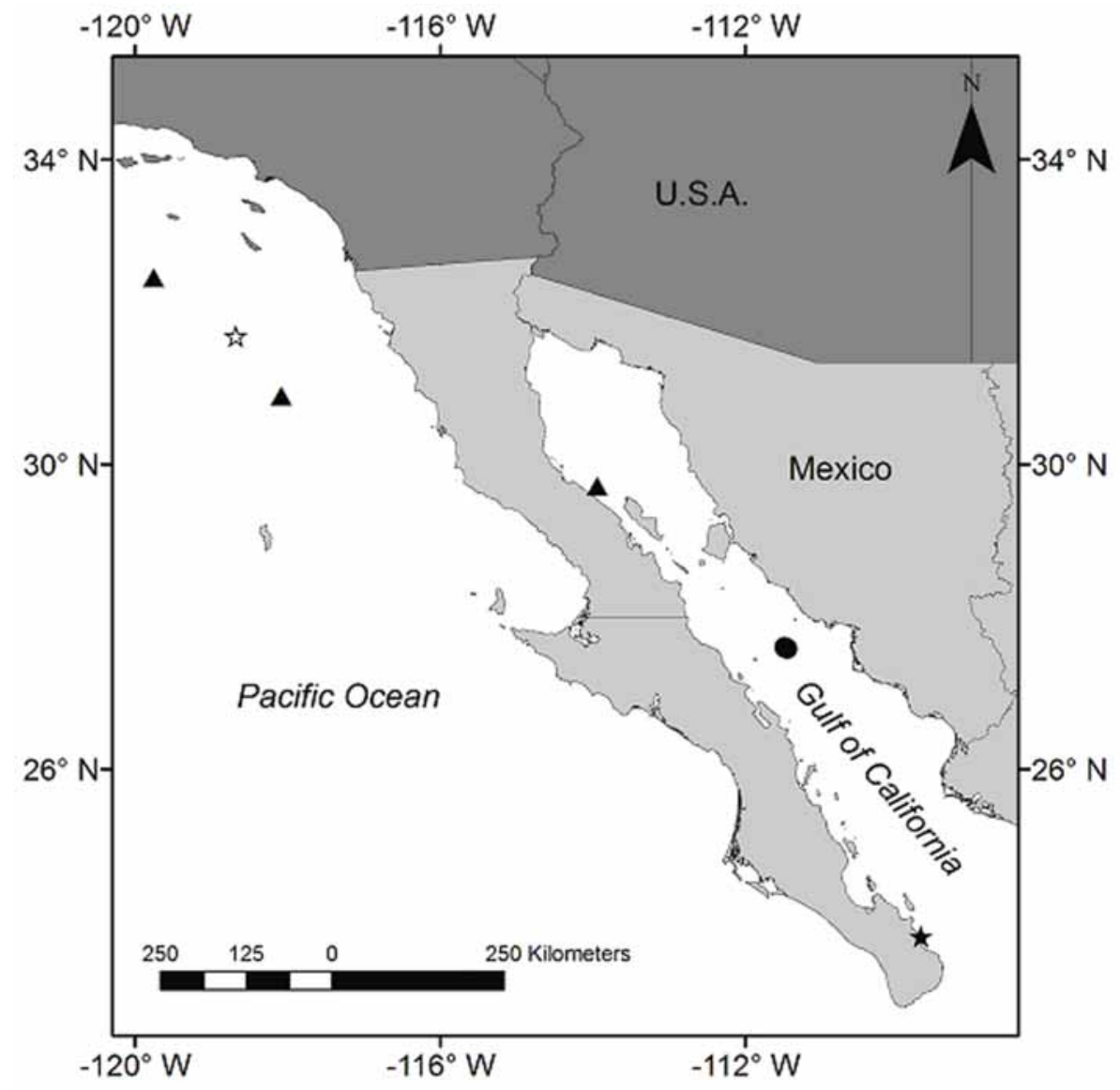

FIGURE 5. Distribution map of the eastern north Pacific region of Hydrolagus melanophasma sp. nov. Filled star is location of holotype collection, open star is location of paratype collection, filled circle is location of ROV video footage and filled triangles are locations of nontype specimen collection (SIO 68-89, SIO 65-435, LACM 37753-1). Map produced courtesy of Joseph Bizzarro (PSRC). 
First dorsal fin preceded by prominent, slightly curved dorsal spine that is attached to the first dorsal fin for $82.8 \%$ (87.2\%) of spine total length; dorsal fin spine long, $25.9 \%$ BDL (25.9\%), height greater than apex of first dorsal fin; posterior edge of spine serrated for last $6.8 \%(13.1 \%)$ of spine length; spine serrations very worn on each specimen. Dorsal spine and first dorsal fin overlap with second dorsal fin when laid flat. First dorsal fin triangular, base short $15.3 \%$ BDL (13.9\%), with concave posterior margin. Second dorsal fin long, uniform in height throughout, and its base length $81.1 \%$ BDL (77.3\%). Depth of second dorsal fin, 4.0\% BDL $(4.1 \%)$, is greater than depth of dorsal lobe of caudal fin, $2.0 \%$ BDL $(3.3 \%)$. There is no measurable separation between insertion of the second dorsal fin and the origin of the caudal fin dorsal lobe. Depth of dorsal and ventral caudal fin lobes is nearly equal. Ventral lobe of caudal fin extends $24.8 \%$ (27.0\%) of its length beyond the insertion of the dorsal lobe of caudal fin. Anal fin lacking.

Trifid claspers present in mature males along with frontal tenaculum and prepelvic tenacula. Claspers forked for posterior most $27.0 \%$ (27.8\%) of total clasper length and extend beyond distal edge of pelvic fins. Prepelvic tenacula are $25.1 \%(17.8 \%)$ of total clasper length with 3 or 4 denticles along the medial edge. Frontal tenaculum is $14.8 \%$ (14.3\%) of HDL with indistinct rows of 35-38 pointed, needle-like denticles.

Lateral line canal measurements of the holotype and paratype are presented in Table 2 . The head lateral line canals are open grooves with wide dilation on the snout. There is a distinct space on the holotype between the preopercular and oral canals where they branch separately from the infraorbital canal (Fig 3A). The paratype exhibits preopercular and oral canals that share a short common branch from the infraorbital (Fig 3B). The preopercular canal is discontinuous after it branches from the oral or infraorbital extending for $24.0 \%$ of HDL or less before breaking into consecutively smaller pieces. Trunk lateral line extends the length of the body from junction with post-orbital to whip-like filament and is generally straight with no regular undulations.

Color. Coloration in life as observed in situ by MBARI ROV footage appears uniform black with a lighter band over the snout slightly anterior to the midpoint between the eye and the snout tip (Fig. 4). After preservation specimens are uniform dark brown or purplish, including all paired and unpaired fins, with no distinct markings or mottling. Claspers are slightly lighter in color.

Etymology. The specific name is derived from melano- (Greek prefix) meaning black and -phasma (Greek noun) meaning specter or spirit. Vernacular: Eastern Pacific Black Ghostshark

Comparisons. Hydrolagus melanophasma is the fifth described species of Hydrolagus now known to occur in the eastern Pacific. Three species, Hydrolagus alphus, H. mccoskeri, and H. macrophthalmus, occur in the southeastern Pacific with the former two considered to be endemic to the Galapagos Islands (Barnett et al. 2006, Quaranta et al. 2006). Hydrolagus alphus is distinct from H. melanophasma in coloration, being uniform brown with a distinct white spot above the pectoral fins, an explicit depressed middle region of the second dorsal fin, a larger eye length (9.5-10.2\% BDL vs. $6.5 \%$ BDL), a shorter second dorsal fin base length (66.3-70.5\% BDL vs. 77.3-81.1\% BDL), and a longer dorsal spine height (30.1-33.2\% BDL vs. 25.9\% BDL) (Quaranta et al. 2006). Hydrolagus mccoskeri is also distinct from H. melanophasma in coloration, being medium brown dorsally with many irregular circular and elongate white blotches, an indented second dorsal fin, a longer snout-vent length (64-67\% BDL vs. 56.9-60.1\% BDL), a longer eye length (9-13\% BDL vs. 6.5\% BDL), and a longer pre-second dorsal fin length (54\% BDL vs. 47.4-47.8\% BDL) (Barnett et al. 2006). Hydrolagus macrophthalmus is known only from off the coasts of Chile and Peru (Quaranta et al. 2006). It is distinct from H. melanophasma in coloration, being uniform brown with no white markings, bluish fins, a second dorsal fin height that is higher at the anterior and posterior ends with a depressed mid-section, a shorter head length (18.6-22.2\% BDL vs. 25-29.5\% BDL), smaller pectoral fins with the anterior edge measuring 31.9-35.3\% BDL (vs. 38.5-40.9\% BDL), and a longer spine (26.3-31.1\% BDL vs. 25.9\% BDL) (K.L. Quaranta, Moss Landing Marine Laboratories, pers. comm.).

Hydrolagus colliei is the only Hydrolagus species, besides H. melanophasma, known to occur in the eastern North Pacific. The distribution of $H$. colliei is from southeastern Alaska to Baja California and the northern Gulf of California. Hydrolagus colliei is distinct from H. melanophasma in coloration, being uniformly dark brown to reddish-brown with numerous white spots on the head and trunk, a strongly indented 
second dorsal fin, a shorter second dorsal fin base length (57-72\% BDL vs. 77.3-81.1\% BDL), a longer distance from origin of the second dorsal fin to origin of pectoral fin (37-53\% BDL vs. 16.4-19.6\% BDL), and a longer snout-vent length (67-93\% BDL vs. 56.9-60.1\% BDL) (Didier and Rosenberger 2002).

Hydrolagus melanophasma is known from southern California and Baja California with most records from the Gulf of California. Hydrolagus melanophasma is considered a deep-water species despite the shallow depth of the holotype collection. It typically occurs deeper than $H$. colliei, which is known to occur from surface waters in the northern part of its range to $971 \mathrm{~m}$ at the southern end of its range (Ebert 2003). Documented collections of $H$. melanophasma are as follows: the holotype at $30.5 \mathrm{~m}$, the paratype at $915 \mathrm{~m}$, four specimens (SIO 68-89) between 565 and $644 \mathrm{~m}$, two specimens (SIO 65-435) at $1155 \mathrm{~m}$, and one specimen (LACM 37753-1) at 1400 m. MBARI ROV footage captured individuals between 1549 and 1667 m.

Remarks. Several live individuals of $H$. melanophasma were observed on ROV video footage from MBARI surveys of the Gulf of California in 2003 (Fig. 4). Geographic coordinates of the underwater footage are $455 \mathrm{~km}$ north of where the holotype was collected and $335 \mathrm{~km}$ south of known collections of $H$. melanophasma in the Gulf of California (Figure 5). Live specimen observations led to insight on coloration in life, habitat selection and behavioral associations and traits.

ROV observations from four transects suggest that $H$. melanophasma individuals typically occur over soft-bottom habitats or cobble patches with minimal vertical relief. Each specimen had a close association with the sea floor, within a few meters, but was not resting on the bottom. Most observations were over flat, soft-sediment habitat. One individual was observed over a small cobble patch surrounded by soft substrate. This is in contrast to other species of eastern Pacific Hydrolagus, such as H. alphus (Quaranta et al. 2006) and H. mccoskeri (Barnett et al. 2006), that are known to associate with areas of high rocky relief. Water clarity of H. melanophasma observations was always poor with the presence of large suspended particulate matter.

The behavior of $H$. melanophasma individuals was to take flight and quickly swim away when approached by the ROV. All individuals of H. melanophasma were observed swimming, never resting on the seafloor. Movements were quick and most often directed away from the ROV; if the ROV attempted to follow an individual, it would rapidly swim out of the field of view. This behavior towards the ROV is in contrast to other species of chimaera that appear either indifferent to its presence, e.g. Harriotta raleighana, or in fact would approach it, e.g. Hydrolagus spp., which were video-taped around seamounts off central California (Ebert 2003), and were observed to approach the ROV, swimming back and forth around it, and even bumping it.

Hydrolagus melanophasma was documented to co-occur with conspecifics and other species of chimaeras. On one ROV transect, two individuals of $H$. melanophasma were observed together before both left the camera's field of vision. On another transect an individual of $H$. melanophasma was seen shortly after Harriotta raleighana, with both individuals occurring over soft-bottom substrate at about $1550 \mathrm{~m}$. Underwater surveys, like those conducted by MBARI, are essential to further our understanding of the deepsea and its diverse inhabitants.

Comparative Material. Hydrolagus mccoskeri - 2 specimens. CAS 86558, holotype juvenile female, $381 \mathrm{~mm}$ TL, $211 \mathrm{~mm}$ BDL, southeast of San Cristobal Island, Galapagos (01⒌981'S 89¹2.235'W), 296.24 m, collected by J.E. McCosker (CAS), R. Grant Gilmore (Harbor Branch Oceanographic Institution) and Bruce Robison (MBARI), 17 Nov. 1995 (JSL dive 3934); CAS 223971, paratype, juvenile female, $227 \mathrm{~mm}$ TL, $107 \mathrm{~mm}$ BDL, off Isla Española, Galapagos, (01 $\left.{ }^{\circ} 5.981^{\prime} \mathrm{S}, 89^{\circ} 45.5^{\prime} \mathrm{W}\right), 505.97 \mathrm{~m}$, collected by J.E. McCosker (CAS), and John Ross (Smithsonian Magazine), 6 Jul. 1998 (JSL dive 3094).

Hydrolagus alphus - 2 specimens. CAS 201902, holotype, adult male, $419 \mathrm{~mm}$ TL, $249 \mathrm{~mm}$ BDL, North end of Seymour Island, Galapagos ( $0^{\circ} 21^{\prime} 42^{\prime \prime}$ S, 90 $\left.90^{\circ}{ }^{\prime} 0^{\prime \prime} \mathrm{W}\right), 648 \mathrm{~m}$, collected by J.E. McCosker (CAS) and Carole Baldwin (United States National Museum), 25 July 1998 (JSL dive 3113); CAS 86425, paratype, subadult female, $480 \mathrm{~mm}$ TL, $244 \mathrm{~mm}$ BDL, Fernandina Island, Galapagos ( $0^{\circ} 14.461^{\prime} \mathrm{S} 91^{\circ} 26.535^{\prime} \mathrm{W}-$ $\left.0^{\circ} 14.820^{\prime} \mathrm{S} 91^{\circ} 26.410^{\prime} \mathrm{W}\right), 731.52 \mathrm{~m}$, collected by J.E. McCosker (CAS), R. Grant Gilmore (HBOI) and Bruce Robison (MBARI), 17 Nov. 1995 (JSL dive 3958) 
Hydrolagus macrophthalmus - 4 specimens. MNHNC P. 7282, holotype, adult male, 385 mm TL, 296 mm BL, preabyssmal zone off Valparaiso, January, 1959; MNHNC P. 5724, adult male, $445 \mathrm{~mm}$ TL, $296 \mathrm{~mm}$

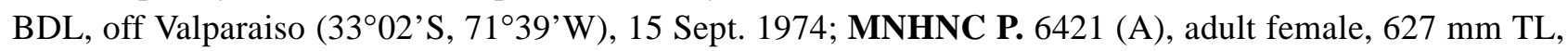

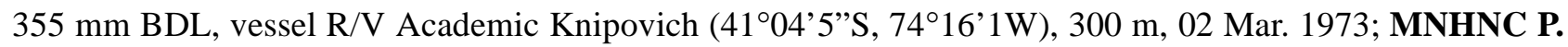
6421 (B), adult female, 572 mm TL, 424 mm BDL, vessel R/V Academic Knipovich (4104'5"S, 74¹6'1'W) 300 m, 02 Mar. 1973.

\section{Acknowledgements}

We would like to thank the following individuals for their invaluable assistance with this project: H.J. Walker Jr. (Scripps Institution of Oceanography), Lonny Lundsten and Kim Fulton-Bennett (Monterey Bay Aquarium Research Institute), Dave Catania (California Academy of Sciences), Jeffrey A. Seigel (Los Angeles County Museum of Natural History) Kim Quaranta (Moss Landing Marine Laboratories) and Joseph Bizzarro (Pacific Shark Research Center, Moss Landing Marine Laboratories). This study was funded by NOAA/NMFS to the National Shark Research Consortium, Pacific Shark Research Center.

\section{References}

Barnett, L.K., Didier, D.A., Long, D.J. \& Ebert, D.A. (2006) Hydrolagus mccoskeri sp. nov., a new species of chimaeroid fish from the Galapagos Islands (Holocephali: Chimaeriformes: Chimaeridae). Zootaxa, 1328, 27-38.

Compagno, L.J.V., Stehmann, M. \& Ebert, D.A. (1990) Rhinochimaera africana, a New Longnose Chimaera from Southern Africa, with Comments on the Systematics and Distribution of the Genus Rhinochimaera Garman, 1901 (Chondrichthyes, Chimaeriformes, Rhinochimaeridae). African Journal of Marine Science, 9, 201-222.

Didier, D.A. (2002) Two New Species of Chimaeroid Fishes from the Southwestern Pacific Ocean (Holocephali, Chimaeridae). Ichthyological Research, 49, 299-306.

Didier, D.A. (2004) Phylogeny and Classification of Extant Holocephali. In. Carrier, J.C., J.A. Musick, and M.R. Heithaus (eds.) Biology of Sharks and Their Relatives. CRC Press, Boca Raton, 115-135.

Didier, D.A. (2008) Two new species of the genus Hydrolagus Gill (Holocephali: Chimaeridae) from Australia. In. Last, P.R., W.T. White and J.J. Pogonoski (eds.) Descriptions of New Australian Chondrichthyans. CSIRO Marine and Atmospheric Research Paper. No. 022. 349-356.

Didier, D.A., \& Rosenberger, L.J. (2002) The Spotted Ratfish, Hydrolagus colliei: Notes on its Biology with a Redescription of the Species (Holocephali: Chimaeridae). California Fish and Game, 88(3), 112-125.

Didier, D.A. \& Seret, B. (2002) Chimaeroid Fishes of New Caledonia with Description of a New Species of Hydrolagus (Chondrichthyes, Holocephali). Cybium, 26(3), 225-233.

Ebert, D.A. (2003) Sharks, Rays, and Chimaeras of California. University of California Press, Berkeley, California, 284 p.

Eschmeyer, W.N. \& Fricke, R. (eds.) Catalog of Fishes electronic version (updated 13 Mar. 2009). http:// research.calacademy.org/ichthyology/catalog/fishcatsearch.html

Eschmeyer, W.N., Herald, E.S. \& Hammann, H. (1983) A Field Guide to Pacific Coast Fishes of North America. Houghton Mifflin Company, Boston, USA.

Hubbs, C.L., Follett, W.I. \& Dempster, L.J. (1979) List of the Fishes of California. Occasional Papers of the California Academy of Sciences. No. 133, 55 pp.

Leviton, A.E., Gibbs Jr., R.H., Heal, E. \& Dawson, C.E. (1985) Standards in Herpetology and Ichthyology: Part I. Standard Symbolic Codes for Institutional Resource Collections in Herpetology and Ichthyology. Copeia, 1985(3), 802-832.

Love, M.S., Mecklenburg, C.W. \& Thorsteinson, L.K. (2005) Resource Inventory of Marine and Estuarine Fishes of the West Coast and Alaska: A Checklist of North Pacific and Arctic Ocean Species from Baja California to the AlaskaYukon Border. U.S. Department of the Interior, U.S. Geological Survey, Biological Resources Division, Seattle, Washington.

Quaranta, K.L., Didier, D.A., Long, D.J. \& Ebert, D.A. (2006) A new species of chimaeroid, Hydrolagus alphus sp. nov. (Chimaeriformes: Chimaeridae) from the Galapagos Islands. Zootaxa, 1377, 33-45. 


\section{Appendix 1. List of morphometric abbreviations used in Tables 1 and 2}

Measurements of the body included: total length (TL); precaudal length (PCL), snout tip to origin of dorsal lobe of caudal fin; body length (BDL), dorsal edge of gill opening to origin of dorsal lobe of caudal fin; snout-vent length (SVL), snout tip to vent opening; trunk length (TRL), ventral edge of gill opening to vent opening; head length (HDL), snout tip to dorsal edge of gill opening; pre-oral length (POR), snout tip to end of upper labial fold; prenarial length (PRN), snout tip to anterior end of nasal apertures; pre-orbital length (POB), snout tip to anterior edge of orbit; eye length (EYL); eye height (EYH); pre-second dorsal length (PD2), snout tip to origin of second dorsal fin; pre-first dorsal length (PD1), snout tip to origin of first dorsal fin; (D1B), length of first dorsal fin base; (DSA), dorsal spine height; (D1H), maximum height of first dorsal fin; (D2B), length of second dorsal fin base; (D2H), maximum height of second dorsal fin; interdorsal space (IDS); dorsal caudal margin length (CDM), from origin to insertion of dorsal caudal lobe; $(\mathrm{CDH})$, maximum height of dorsal lobe of caudal fin; total caudal length (CTL), from origin of dorsal caudal lobe to end of caudal filament; ventral caudal margin (CVM), from origin to insertion of ventral caudal lobe; $(\mathrm{CVH})$, maximum height of ventral lobe of caudal fin; caudal peduncle height $(\mathrm{CPH})$, measured at origin of dorsal lobe of caudal fin; pectoral fin anterior margin (P1A); pelvic fin anterior margin $(\mathrm{P} 2 \mathrm{~A})$; $(\mathrm{P} 2 \mathrm{P})$, posterior base of pectoral fin to anterior base of pelvic fin; pelvic-caudal space (PCA), insertion of pelvic fin to origin of ventral caudal lobe; (D1P1), origin of first dorsal fin to origin of pectoral fin; (D1P2), origin of first dorsal fin to origin of pelvic fin; (D2P1), origin of second dorsal fin to origin of pectoral fin; (D2P2), origin of second dorsal fin to origin of pelvic fin; total clasper length (CLT), from pelvic fin base to tip; (CLM), length of medial clasper branch from fork to tip; (CLL), length of lateral clasper branch from fork to tip; and frontal tenaculum length (FTL), measured from rear end of base to anterior tip.

Lateral line canal measurements: (ONC), distance from anterior oronasal fold to center of nasal canal; (LRC), length of rostral canal; (LNC), length of nasal canal from left to right side measured as a straight-line distance; (IOA), straight-line distance between infraorbital and angular canal measured from junction of the oral and infraorbital canal to the junction of the oral and angular canal; (OTM), distance between preopercular canal and main trunk canal measured from their junction with the infraorbital canal; (OCL), distance between main trunk canal and supratemporal canal measured from their junctions with the infraorbital and postorbital canal respectively; (STL), length of supratemporal canal measured across the head from its junctions with the postorbital canal; and (SPS), distance from anterior base of spine to the center of the supratemporal canal. 